\title{
Sperm retrieval rate and pregnancy rate in infertile couples undergoing in-vitro fertilisation and testicular sperm extraction for non- obstructive azoospermia in Hong Kong
}

\author{
Jennifer KY Ko *, Joyce Chai, Vivian CY Lee, Raymond HW Li, Estella Lau, KL Ho, PC Tam, \\ William SB Yeung, PC Ho, Ernest HY Ng
}

\section{A B S T R A C T}

Objective: There are currently no local data on the sperm retrieval and pregnancy rates in in-vitro fertilisation and testicular sperm extraction cycles, especially with regard to the presence of genetic abnormalities. This study aimed to determine the sperm retrieval and pregnancy rates in infertile couples who underwent in-vitro fertilisation and testicular sperm extraction for non-obstructive azoospermia.

Methods: This retrospective case series was conducted at a tertiary assisted reproduction unit in Hong Kong. Men with non-obstructive azoospermia who underwent in-vitro fertilisation and testicular sperm extraction between January 2001 and December 2013 were included. The main outcome measures were sperm retrieval and pregnancy rates.

Results: During the study period, 89 men with non-obstructive azoospermia underwent in-vitro fertilisation and testicular sperm extraction. Sperm was successfully retrieved in 40 (44.9\%) men. There was no statistically significant difference in the sperm retrieval rate of those with karyotypic abnormalities $(2 / 5,40.0 \%$ vs $28 / 61,45.9 \%$; $\mathrm{P}=1.000)$ and AZFc microdeletion ( $3 / 6,50.0 \%$ vs $28 / 61,45.9 \%$; $\mathrm{P}=1.000)$ compared with those without. Sperms were successfully retrieved in patients who had mosaic Klinefelter syndrome $(2 / 3,66.7 \%)$ but not in the patient with non-mosaic Klinefelter syndrome. No sperms were found in men with AZFa or AZFb microdeletions. Pregnancy test was positive in 15

This article was published on 30 Sep 2016 at www.hkmj.org. (16.9\%) patients and the clinical pregnancy rate was

per transfer was $34.3 \%(12 / 35)$.

Conclusions: The sperm retrieval rate and clinical pregnancy rate per initiated cycle in men undergoing in-vitro fertilisation and testicular sperm extraction in our unit were $44.9 \%$ and $13.5 \%$, respectively. No sperms could be retrieved in the presence of AZFa and AZFb microdeletions, but karyotype and AZFc microdeletion abnormalities otherwise did not predict the success of sperm retrieval in couples undergoing in-vitro fertilisation and testicular sperm extraction. Genetic tests are important prior to testicular sperm extraction for patient selection and genetic counselling.

Hong Kong Med J 2016;22:556-62

DOI: $10.12809 / \mathrm{hkmj} 154710$

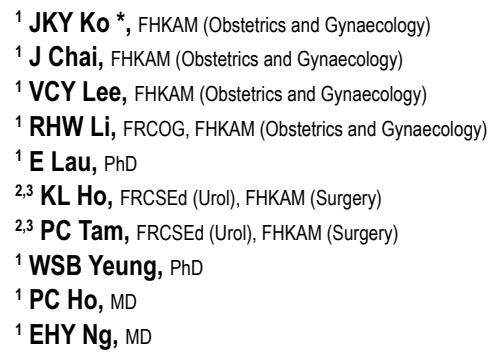

JKY Ko *, FHKAM (Obstetrics and Gynaecology)

1 J Chai, FHKAM (Obstetrics and Gynaecology)

${ }^{1}$ VCY Lee, FHKAM (Obstetrics and Gynaecology)

${ }^{1}$ RHW Li, FRCOG, FHKAM (Obstetrics and Gynaecology)

${ }^{1} \mathrm{E}$ Lau, PhD

${ }^{2,3}$ KL Ho, FRCSEd (Urol), FHKAM (Surgery)

${ }^{2,3}$ PC Tam, FRCSEd (Urol), FHKAM (Surgery)

${ }^{1}$ WSB Yeung, PhD

${ }^{1} \mathrm{PC} \mathrm{Ho}, \mathrm{MD}$

${ }^{1} \mathrm{EHY} \mathrm{Ng}, \mathrm{MD}$

Department of Obstetrics and Gynaecology, The University of Hong Kong, Queen Mary Hospital, Pokfulam, Hong Kong

Division of Urology, Department of Surgery, The University of Hong Kong, Queen Mary Hospital, Pokfulam, Hong Kong

Private practice

* Corresponding author: jenko@hku.hk

New knowledge added by this study

- Our study provides important local data for counselling of men with non-obstructive azoospermia. The sperm retrieval rate and clinical pregnancy rate per cycle in men undergoing in-vitro fertilisation and testicular sperm extraction in our unit were $44.9 \%$ and $13.5 \%$, respectively.

- There was no statistically significant difference in the sperm retrieval and pregnancy rates in those with karyotypic abnormalities and AZFc microdeletion compared with those without. Sperms, however, were not found in men with AZFa or AZFb microdeletions.

Implications for clinical practice or policy

- Although karyotype abnormalities and AZFc microdeletion did not affect the sperm retrieval and pregnancy rates in couples undergoing in-vitro fertilisation and testicular sperm extraction, karyotype and Y-microdeletion should be checked in men with non-obstructive azoospermia. The risk of vertical transmission of genetic abnormalities should be discussed and couples should be offered appropriate genetic counselling before treatment. 


\section{Introduction}

Male-factor infertility is involved in about half of all infertile couples who seek assisted reproduction treatment. ${ }^{1}$ The advent of in-vitro fertilisation (IVF) with intracytoplasmic sperm injection (ICSI) has allowed many men with severe male factor to have their own genetic child. ${ }^{2}$ The development of surgical sperm retrieval techniques by testicular sperm extraction (TESE) has extended the possibility of fatherhood to those with non-obstructive azoospermia (NOA). ${ }^{3}$

The reported sperm retrieval rate from TESE varies in different studies due to inclusion of different populations, but is generally quoted to be around $50 \%{ }^{4}$ Nevertheless TESE is invasive. In a recent retrospective cohort study by Vloeberghs et $\mathrm{al}^{5}$ only one (14.3\%) out of seven men undergoing IVFTESE eventually became a biological father. Studies have also shown a high prevalence of chromosomal abnormalities and Y-microdeletion in infertile men with NOA or severe oligozoospermia. ${ }^{6-9}$ These genetic abnormalities can potentially be transmitted vertically resulting in a child with sex aneuploidies or boys with the same Y-microdeletion. ${ }^{10}$ Guidelines from the American Society for Reproductive Medicine, American Urological Association, Canadian Urological Association, and International Federation of Fertility Societies are unanimous in suggesting that all men with NOA due to testicular failure should be offered genetic testing to exclude chromosomal abnormalities and $\mathrm{Y}$ chromosome microdeletions, and that genetic counselling be offered if an abnormality is detected. ${ }^{11-14}$

There are currently no local data on the sperm retrieval and pregnancy rates in IVF-TESE cycles, especially with regard to the presence of genetic abnormalities. Such information is invaluable to couples in pretreatment counselling and could affect their decision about treatment options. In this study, we determined the sperm retrieval and pregnancy rates in infertile couples who underwent IVF-TESE for NOA.

\section{Methods}

The study was a retrospective analysis of couples who underwent the first IVF cycle and required TESE for NOA at Queen Mary Hospital, a university affiliated tertiary care hospital, from January 2001 to December 2013. They were identified from our assisted reproductive technique database. Ethics approval was obtained from the Institutional Review Board of the University of Hong Kong / Hospital Authority Hong Kong West Cluster, with the requirement of patient informed consent waived because of its retrospective nature.

Husbands who attended our subfertility clinic were requested to submit one semen sample to the
香港非梗阻性無精子症患者接受體外受精和睪丸 精子提取後的取精成功率和隨後的妊娠率

\section{高嘉意、柴逸蘭、李芷茵、李幸奐、劉綺蘭、何崑崙、 \\ 談寶雛、楊樹標、何柏松、吳鴻裕}

目的：香港目前並沒有體外受精和睪丸精子提取（IVF-TESE）的本 地數據, 尤其是與遺傳異常相關的資料。本研究旨在找出非梗阻性無 精子症 (NOA) 患者接受IVF-TESE後的取精成功率以及隨後的妊娠 率。

方法：本回顧性病例系列研究於香港一所三級輔助生育技術中心內 進行。研究對象為2001年1月至2013年12月期間曾接受IVF-TESE的 NOA患者。主要結果測量為參與者的取精成功率以及隨後的妊娠率。

結果 : 研究期間共 89 名NOA患者接受IVF-TESE。40案例成功提取精 子, 成功率為 $44.9 \%$ 。比較核型異常與正常的病例並無發現統計學顯 著差異 $(2 / 5,40.0 \%$ 比 $28 / 61 ， 45.9 \% ； \mathrm{P}=1.000)$; Y染色體AZFc區 微缺失與沒有缺失的病例同樣並無統計學顯著差異 ( $3 / 6,50.0 \%$ 比 28/61，45.9\%；P=1.000）。3例鑲嵌型Klinefelter症候群患者中2例 (66.7\%) 成功提取精子, 但非鑲嵌型Klinefelter症候群患者則未能成 功。未有發現AZFa區和AZFb區微缺失患者有精子。15例（16.9\%）成 功妊娠, 周期臨床妊娠率為 $13.5 \%$ （12/89）。移植周期臨床妊娠率為 $34.3 \%$ ( $12 / 35$ )

結論 : 接受IVF-TESE的周期取精成功率為 $44.9 \%$, 周期妊娠率為 $13.5 \% \circ \mathrm{AZFa}$ 區和 $\mathrm{AZFb}$ 區微缺失患者未能成功提取精子, 但核型異常 及AZFc區微缺失並不能預測能否成功提取精子。IVF-TESE前進行基 因測試對於病例選擇及病人遺傳諮詢相當重要。

andrology laboratory of our centre prior to the first consultation. If the first semen analysis was abnormal, they were asked to submit a second semen sample. Semen analysis was based on the criteria of the World Health Organization $(1999,2010) .{ }^{15,16}$ Those with azoospermia confirmed in two semen samples following centrifugation were referred to the male infertility clinic for further assessment by urologists. All patients had detailed urological and reproductive history, physical examination, and hormonal profile including morning serum testosterone, follicle-stimulating hormone (FSH), and luteinising hormone. ${ }^{17}$ Men with azoospermia deemed to be due to a non-obstructive cause, as suggested by raised FSH and small testes, were advised to check their karyotype and microdeletion of the $\mathrm{Y}$ chromosome. The detailed techniques for chromosome analysis and Y-microdeletion studies by polymerase chain reaction of DNA from peripheral blood have been previously described. ${ }^{6,9,18}$ Karyotyping was performed by analysis of banded metaphase chromosomes from cultured cells. At least 15 and 30 metaphases were analysed routinely and whenever an anomaly was suspected, respectively. ${ }^{6}$ Y-microdeletion was analysed using six $\mathrm{Y}$ chromosome specific sequence tagged site markers that corresponded to the AZFa (sY84, sY86), AZFb (sY127, sY132), and AZFc (SY254, sY255) regions. ${ }^{6,9,18}$ Information on karyotype and 
Y-microdeletion was obtained from the medical record of the patients, and cross-referenced with the database of the genetic screening for male subfertility at Tsan Yuk Hospital.

Men with NOA who wished to have their own genetic child would be advised to undergo TESE to retrieve sperms. The most common ovarian stimulation protocols used in our unit were the long gonadotropin-releasing hormone $(\mathrm{GnRH})$ agonist and $\mathrm{GnRH}$ antagonist protocols. Details of the stimulation cycle have previously been described. ${ }^{19}$ Patients attended the clinic on day 2 of the treatment cycle. Transvaginal ultrasonography was performed to determine antral follicle count (AFC) and serum oestradiol level was checked. Ovarian stimulation was commenced if the serum oestradiol level was confirmed at basal level and there was no ovarian cyst. The gonadotropin dosage depended on the woman's age, AFC, and previous ovarian response. Transvaginal ultrasound for follicular tracking was performed 7 days after the start of ovarian stimulation and every 1 to 3 days thereafter. Further dosage of gonadotropins was titrated depending on the ovarian response of the patient during follicular tracking. Human chorionic gonadotropin (hCG) was given to trigger final oocyte maturation when the mean diameter of the leading follicle was at least $18 \mathrm{~mm}$ and three or more follicles reached a mean diameter of at least $16 \mathrm{~mm}$. Transvaginal ultrasound-guided oocyte retrieval was performed 34 to 36 hours later.

The urologist was responsible for performing TESE that was performed under general anaesthesia on the day of oocyte retrieval. In conventional TESE, the scrotal skin and tunica vaginalis were opened and the testis was exposed through an incision. Bilateral testicular biopsies from the upper, middle, and lower poles were performed. Microdissection TESE, which involved identification of spermatogenically active areas under high magnification for more targeted biopsies, was performed starting from 2010. The biopsied testicular tissue was minced mechanically with two microscope slides, and incubated for 1 hour to allow the sperms to swim out of the tissue. Enzymatic digestion of the testicular tissue was performed as described when no sperms were seen under microscope. ${ }^{20}$ The testicular sperms were isolated by mini-density gradient centrifugation. Sperms with high density at the bottom of the gradient as well as those in the interface between the gradients were collected in two aliquots of culture medium. Before ICSI, the embryologist searched the sperms first in the whole aliquot containing sperms of high density, and then in the aliquot containing sperms at the interface if no sperm was found in the first aliquot. Spare sperms were cryopreserved. Fertilisation was achieved by ICSI in patients with successful sperm retrieval. One or two embryos were replaced 2 days after retrieval. Luteal phase support was given with either two doses of hCG 1500 IU 5 days apart or vaginal progesterone for 2 weeks after embryo transfer. Patients were followed up with a urinary pregnancy test 16 days after embryo transfer and those with a positive pregnancy test had transvaginal ultrasound scan performed 10 to 14 days later and were referred for antenatal care at 8 to 10 weeks of gestation. Pregnancy outcome was monitored. Pregnancy was defined as a positive urinary pregnancy test. A clinical pregnancy was defined as a pregnancy with the presence of one or more intrauterine sac on transvaginal ultrasound. An ongoing pregnancy was defined as the presence of at least one fetal heart pulsation on ultrasound beyond 20 weeks. When no sperms were retrieved, the collected oocytes were either discarded, donated, or frozen if further treatment with donor sperm was considered.

Data analyses were performed by the Statistical Package for the Social Sciences (Windows version 20.0; SPSS Inc, Chicago [IL], US). Comparisons between the groups were made using the Fisher's exact test, and $\mathrm{P}<0.05$ was considered statistically significant.

\section{Results}

Only information from the first cycle of IVFTESE was included. Of 112 men who underwent TESE during the study period, 23 were excluded from analysis because of non-motile sperms in the ejaculate $(n=3)$, ejaculatory dysfunction $(n=4)$, and obstructive azoospermia and underwent TESE after failed microepididymal sperm aspiration $(n=16)$. Therefore, 89 patients with NOA were included in the analysis.

The mean age of the men was 37.2 (standard deviation [SD], 6.2) years. Of the 85 patients with smoking history available, $59(69.4 \%)$ were nonsmokers and $26(30.6 \%)$ were smokers. Genetic information was missing in nine men. Of 76 men with genetic information available, eight (10.5\%) had karyotypic abnormality-six were sex chromosomal and two were autosomal, as shown in Table 1. The most common sex chromosomal abnormality was Klinefelter syndrome $(3 / 6,50 \%$; 1 non-mosaic and 2 mosaic). The two men with autosomal chromosome abnormality were a ring chromosome 21 and a mosaic supernumerary marker chromosome. Of these 76 men, nine (11.8\%) had microdeletion of the Y chromosome. The most common Y-microdeletion was AZFc microdeletion $(6 / 9,66.7 \%)$. Three men had both chromosomal abnormality and Ymicrodeletion.

Of the 89 patients, sperms were successfully retrieved in $40(44.9 \%)$. There was no statistically significant difference in the sperm retrieval rate in those with karyotype abnormalities and AFZc 
TABLE I. Success of TESE and pregnancy outcome in patients with genetic abnormality

\begin{tabular}{|c|c|c|c|c|c|}
\hline $\begin{array}{l}\text { Patient } \\
\text { No. }\end{array}$ & Karyotypic abnormality & Y-microdeletion & $\begin{array}{l}\text { Presence of } \\
\text { sperms }\end{array}$ & $\begin{array}{l}\text { Outcome of fertilisation (normal } \\
\text { fertilisation/metaphase II) }\end{array}$ & Pregnancy \\
\hline 1 & $47 X X Y$ & - & - & $\mathrm{N} / \mathrm{A}$ & - \\
\hline 2 & $47, X X Y / 46, X(29: 1)$ & - & + & $1 / 3(33.3 \%)$ & - \\
\hline 3 & $46 X Y / 47 X X Y(29: 1)$ & - & + & $9 / 15(60.0 \%)$ & - \\
\hline 4 & $46 X Y / 45 X(33: 1)$ & $\mathrm{AZFb}+\mathrm{C}$ & - & $\mathrm{N} / \mathrm{A}$ & - \\
\hline 5 & 46,X,der(Y).ish i(Y)(p10)(pter++,SRY++) & $A Z F a+b+c$ & - & N/A & - \\
\hline 6 & 45,X/46,X,idic(Y)(q11.2) (12:18) & $\mathrm{AZFb}+\mathrm{C}$ & - & $\mathrm{N} / \mathrm{A}$ & - \\
\hline 7 & $46, X Y, r(21)$ & - & - & $\mathrm{N} / \mathrm{A}$ & - \\
\hline 8 & $47, \mathrm{XY},+\mathrm{mar} / 46, \mathrm{XY}$ & - & - & $\mathrm{N} / \mathrm{A}$ & - \\
\hline 9 & - & AZFc & - & $\mathrm{N} / \mathrm{A}$ & - \\
\hline 10 & - & AZFc & - & $\mathrm{N} / \mathrm{A}$ & - \\
\hline 11 & - & AZFc & - & $\mathrm{N} / \mathrm{A}$ & - \\
\hline 12 & - & AZFc & + & $9 / 15(60.0 \%)$ & - \\
\hline 13 & - & AZFc & + & $1 / 13(7.7 \%)$ & + \\
\hline 14 & - & AZFc & + & $1 / 2(50.0 \%)$ & - \\
\hline
\end{tabular}

Abbreviations: N/A = not applicable;TESE = testicular sperm extraction; + = positive; - = negative

TABLE 2. The relationship between Y-microdeletion and karyotypic abnormalities and success of testicular sperm extraction

\begin{tabular}{lrcc}
\hline & No sperms & Presence of sperms & P value \\
\hline AZFc microdeletion & $3 / 6(50.0 \%)$ & $3 / 6(50.0 \%)$ & 1.000 \\
No Y-microdeletion & $33 / 61(54.1 \%)$ & $28 / 61(45.9 \%)$ & - \\
Karyotype abnormalities (any) & $3 / 5(60.0 \%)$ & $2 / 5(40.0 \%)$ & 1.000 \\
Normal karyotype & $33 / 61(54.1 \%)$ & $28 / 61(45.9 \%)$ & - \\
Sex chromosomal abnormalities & $1 / 3(33.3 \%)$ & $2 / 3(66.7 \%)$ & 0.596 \\
Normal karyotype & $33 / 61(54.1 \%)$ & $28 / 61(45.9 \%)$ & - \\
\hline
\end{tabular}

microdeletion compared with those without(Table 2). The same was true when those with sex chromosomal abnormality were compared with those having normal karyotype. Sperms were retrieved in the two patients with mosaic Klinefelter syndrome but not the one with non-mosaic Klinefelter syndrome. For those with Y-microdeletion, sperms were retrieved in $50 \%(3 / 6)$ with AZFc microdeletions, but no sperms were found in the men with $\mathrm{AZFa}+\mathrm{b}+\mathrm{c}$ and $\mathrm{AZFb}+\mathrm{c}$ microdeletions. The men with $\mathrm{AZFa}+\mathrm{b}+\mathrm{c}$ and $\mathrm{AZFb}+\mathrm{c}$ microdeletions all had co-existing sex chromosomal abnormalities (Table 1).

The mean age of the female partners was 37.2 (SD, 6.2) years. The median dosage of gonadotropins used was $1950 \mathrm{IU}$ (interquartile range, 1650-2550 IU), duration of stimulation 12 days (11-14 days), peak oestradiol level 11341 pmol/L (7859.5-19260.5 $\mathrm{pmol} / \mathrm{L})$, and the number of metaphase II oocytes obtained was 8 (4-13). Pregnancy test was positive in $15 / 89(16.9 \%)$ and the clinical pregnancy rate was
12/89 (13.5\%). Among those with sperms found, pregnancy test was positive in $15 / 40(37.5 \%)$ and the clinical pregnancy rate was $12 / 40(30.0 \%)$. Clinical pregnancy rate per transfer was $12 / 35$ (34.3\%). Two patients had biochemical pregnancy and one had ectopic pregnancy. There were 10 live births-seven singletons and three pairs of twins. One patient underwent second-trimester medical termination of pregnancy for fetal alobar holoprosencephaly. One had an ongoing pregnancy at 12 weeks but was subsequently lost to follow-up. The ongoing pregnancy rate per cycle was $10 / 89$ (11.2\%). The clinical pregnancy rate was not statistically different between those who had karyotypic abnormalities $(0 / 5,0 \%$ vs $8 / 61,13.1 \% ; \mathrm{P}=1.000)$ and $\mathrm{Y}$-microdeletion $(1 / 6,16.7 \%$ vs $8 / 61,13.1 \% ; \mathrm{P}=1.000)$ compared with those who did not. Among the five patients who did not have embryo transfer, two had failed fertilisation, two had no transferrable embryos, and one had no oocyte retrieved. 


\section{Discussion}

Ho et $\mathrm{al}^{17}$ highlighted the importance of male factor in infertility assessment and treatment in a recent case series in a local male infertility clinic. The incidence of azoospermia was reported to be up to $36.2 \%$, of which $52.1 \%$ had a non-obstructive cause and would require TESE. ${ }^{17}$ With increasing awareness of male infertility, it is hoped that more men will seek professional help and share the burden in fertility treatment. Nevertheless, existing data available in the literature on outcomes of IVF-TESE are fragmentary ${ }^{5}$ and local data are still lacking.

Karyotypic abnormalities and Y-microdeletion have been associated with severe male factor infertility. $\mathrm{Fu}$ et $\mathrm{al}^{21}$ demonstrated high rates of chromosomal abnormalities and $\mathrm{Y}$ chromosome microdeletions in Chinese infertile men with azoospermia or severe oligozoospermia. In another local study from our centre, the prevalence of chromosomal abnormality and Y-microdeletion were up to $21.1 \%$ and $8.5 \%$, respectively in the azoospermic group. ${ }^{6}$ The prevalence of sex chromosomal abnormality and Y-microdeletion in the present study was $6 / 76$ (7.9\%) and 9/76 (11.8\%), respectively; the former was lower than that reported by our centre previously. This may be because we only included men who had TESE performed in the current study, and it is possible that some men, particularly those who were found to have genetic abnormality, did not further pursue assisted reproductive treatment considering the anticipated poor prognosis.

Testing for chromosomal abnormalities and Y-microdeletion are recommended as an essential part of the workup of men with NOA or severe oligospermia by the American Society for Reproductive Medicine, ${ }^{13}$ American Urological Association, ${ }^{12}$ Canadian Urological Association, ${ }^{11}$ and International Federation of Fertility Societies guidelines. ${ }^{14}$ In particular, microdeletion of the $\mathrm{AZFa}$ or AZFb regions were associated with poor prognosis of sperm retrieval and no sperms have been retrieved in these patients. ${ }^{22}$ Although our study did not show any statistically significant difference in the sperm retrieval rates in those with karyotype abnormalities and Y-microdeletion compared with those without, it should be noted that all patients who had sperms retrieved were having AZFc microdeletion consistent with existing reports, and those who had AZFabc and AZFbc did not have sperms retrieved. Nonetheless the three men with AZFabc and AZFbc microdeletions all had co-existing sex chromosomal abnormalities that may also have affected spermatogenesis. Men with $\mathrm{AZFa}$ or $\mathrm{AZFb}$ microdeletion are therefore often advised against TESE because of a very low chance of successful retrieval of mature spermatozoa. Given proper counselling, these patients may opt not to pursue further assisted reproductive techniques, and go directly for options including donor insemination or adoption. On the other hand, the majority of men with AZFc microdeletion have sperm available for use. In some studies, AZFc deletion was even associated with an increased likelihood of sperm retrieval. ${ }^{22}$ The sperm retrieval rate in men with Klinefelter syndrome via microdissection TESE has also been reported to be similar or even higher than in those with NOA and normal karyotype. ${ }^{23-25}$ In our experience, sperms were only found in the two patients with mosaic Klinefelter syndrome but not the one with non-mosaic Klinefelter syndrome. Previous studies showed that sperms are more likely to be retrieved in younger men with Klinefelter syndrome. ${ }^{26,27}$ In our study, the man with nonmosaic Klinefelter syndrome was 42 years old and might have passed the window of opportunity for successful sperm retrieval. The two patients with mosaic Klinefelter syndrome were 34 and 47 years old, respectively.

This study provides important information on the prognosis for men with NOA. The sperm retrieval rate of $44.9 \%$ is very similar to a previous report at our centre where sperms were found in $12 / 26(46.2 \%)$ of men. ${ }^{28}$ In that study, the pregnancy rate was $14.3 \%$ per cycle when spermatozoa were injected. Our study showed that the chance for a man with NOA undergoing TESE to father his own child is $13.5 \%$, very similar to that of $13.4 \%$ reported by Vloeberghs et al. ${ }^{5}$ Indeed, Vloeberghs et $\mathrm{al}^{5}$ have only included men with normal karyotype and absence of Y-microdeletion, who were included in our study, and we only included men who underwent first cycle of IVF-TESE. The clinical pregnancy rate would have been higher if we also included men who underwent further attempts. Nonetheless, men were generally advised against further TESE after failure to retrieve sperms in the first attempt owing to the poor prognosis.

Another important issue is the potential for the genetic abnormality to be transmitted vertically via assisted reproductive technology. Couples wherein the male partner has Y-microdeletion should be counselled about the potential for inheritance of compromised fertility by male offspring and proper genetic counselling should be in place before embarking on IVF-TESE.

The practice of our centre was synchronous TESE on the day of oocyte retrieval. Several studies have shown comparable fertilisation and pregnancy rates when TESE is performed beforehand, either on the day before oocyte retrieval ${ }^{29}$ or even prior to initiation of controlled ovarian hyperstimulation. ${ }^{30}$ The merit of the latter approach is that women do not have to go through controlled ovarian stimulation if no sperms can be retrieved, and therefore can avoid the risks of ovarian hyperstimulation syndrome and 
the costs involved. The available cryopreservationthawing procedure for sperms leads to sperm loss however, and there is still a possibility that the cycle will have to be cancelled if there are no viable sperms after thawing.

As $50 \%$ of couples undergo IVF-TESE in vain, with resulting psychological and financial implications, research into various factors that could predict successful sperm retrieval is important. Previous findings from our retrospective study did not suggest any significant differences in the age, history of mumps or orchitis/oligozoospermia, volume of both testes, serum FSH and testosterone levels in men with or without spermatozoa in IVFTESE cycles. $^{28}$ Indeed, no individual biochemical or hormonal marker has been found to reliably predict success in TESE. ${ }^{31}$ Although histopathology of testicular biopsy has been shown to predict TESE outcome, it is invasive and usually done at the time of TESE itself rather than beforehand in many patients, limiting its role as a predictive marker. ${ }^{31}$ The detection of Y chromosome microdeletion, especially AZFa and $\mathrm{AZFb}$, was important to guide prognosis as discussed above. Ramasamy et $\mathrm{al}^{32}$ showed that high serum FSH level in men did not affect the success of microdissection TESE and should not be used to deny men the possibility to father a child with their own genetic material. ${ }^{14}$ Similarly, testicular size may represent poor spermatogenesis in general but does not consistently predict sperm retrieval rate. ${ }^{31}$ In a meta-analysis, serum inhibin B had a sensitivity of 0.65 and a specificity of 0.83 in prediction of successful TESE but it was still suboptimal as a single predictive criterion. ${ }^{33}$ Seminal anti-Müllerian hormone and inhibin B are secreted by the Sertoli cells into the seminiferous tubules and therefore in theory are more direct markers of spermatogenesis, but their predictive value for successful TESE was not confirmed in a prospective study of 139 men with NOA by Mitchell et al. ${ }^{34} \mathrm{~A}$ combination of factors have been shown to fare better, and authors have described the use of a predictive score involving the total testicular volume, FSH, and inhibin B to predict the sperm retrieval rate in NOA. ${ }^{35}$

There are several limitations to our study. The number of men who declined genetic testing or TESE was not known. These men may be those with anticipated poor prognosis such that our study has included those with 'better' prognosis and therefore a higher sperm retrieval rate. In addition, while some authors suggest that hormonal profile or testicular volume may have provided prognostic information, ${ }^{35,36}$ our information on hormonal profile of men was incomplete. Prior to TESE, FSH might have been checked up to 2 years because of the long waiting list for IVF, and therefore was not analysed in this study. Other important limitations are the small number of cases and retrospective nature of our study that precludes proper statistical analysis. When pregnancy outcome is analysed, it is essential to remember the other confounding variables of the female partner such as age and diagnostic category that limit the conclusions that can be drawn. Moreover, as the study spanned over 13 years, there have been changes such as surgical techniques. Men included in the earlier years underwent TESE while those more recently underwent microdissection TESE. Further studies looking into different prognostic factors to predict successful sperm retrieval are needed.

\section{Conclusions}

The sperm retrieval rate and clinical pregnancy rate per cycle in men undergoing IVF-ICSI-TESE in our unit were $44.9 \%$ and $13.5 \%$, respectively. Karyotype and AZFc microdeletion abnormalities did not predict the success of sperm retrieval or clinical pregnancy rate in couples undergoing IVF-ICSI-TESE in the present case series, but are important in patient counselling. Consistent with existing literature, no sperms could be retrieved in individuals with AZFa and AZFb microdeletions.

\section{Acknowledgements}

We would like to thank Mr Tak-ming Cheung for data management, and the laboratory colleagues of Prenatal Diagnostic Laboratory at Tsan Yuk Hospital who have helped trace the karyotype and Y-microdeletion results.

\section{Declaration}

All authors have disclosed no conflicts of interest.

\section{References}

1. Infertility diagnosis by age of patients receiving RT procedures (other than DI and AIH) in 2013. Council on Human Reproductive Technology. Available from: http:// www.chrt.org.hk/english/publications/files/table17_2013. pdf. Accessed 6 Jul 2015.

2. Devroey P, Van Steirteghem A. A review of ten years experience of ICSI. Hum Reprod Update 2004;10:19-28.

3. Devroey P, Liu J, Nagy Z, et al. Pregnancies after testicular sperm extraction and intracytoplasmic sperm injection in non-obstructive azoospermia. Hum Reprod 1995;10:145760.

4. Donoso P, Tournaye H, Devroey P. Which is the best sperm retrieval technique for non-obstructive azoospermia? A systematic review. Hum Reprod Update 2007;13:539-49.

5. Vloeberghs V, Verheyen G, Haentjens P, Goossens A, Polyzos NP, Tournaye H. How successful is TESE-ICSI in couples with non-obstructive azoospermia? Hum Reprod 2015;30:1790-6.

6. Ng PP, Tang MH, Lau ET, et al. Chromosomal anomalies and Y-microdeletions among Chinese subfertile men in Hong Kong. Hong Kong Med J 2009;15:31-8.

7. Chiang HS, Wei HJ, Chen YT. Genetic screening for patients 
with azoospermia and severe oligo-asthenospermia. Int J Androl 2000;23 Suppl 2:20-5.

8. Chandley AC. Chromosome anomalies and Y chromosome microdeletions as causal factors in male infertility. Hum Reprod 1998;13 Suppl 1:45-50.

9. Tse JY, Yeung WS, Lau EY, Ng EH, So WW, Ho PC. Deletions within the azoospermia factor subregions of the $\mathrm{Y}$ chromosome in Hong Kong Chinese men with severe male-factor infertility: controlled clinical study. Hong Kong Med J 2000;6:143-6.

10. Lee SH, Ahn SY, Lee KW, Kwack K, Jun HS, Cha KY. Intracytoplasmic sperm injection may lead to vertical transmission, expansion, and de novo occurrence of Ychromosome microdeletions in male fetuses. Fertil Steril 2006;85:1512-5.

11. Jarvi K, Lo K, Grober E, et al. The workup and management of azoospermic males. Can Urol Assoc J 2015;9:229-35.

12. Jarow J, Sigman M, Kolettis PN, et al. The evaluation of the azoospermic male: AUA Best Practice Statement (revised 7/22/11). US, Maryland: American Urological Association Education and Research, Inc; 2011.

13. Practice Committee of the American Society for Reproductive Medicine in collaboration with the Society for Male Reproduction and Urology. Evaluation of the azoospermic male. Fertil Steril 2008;90(5 Suppl):S74-7.

14. Standards and Practice Committee. International Federation of Fertility Societies. Global standards of infertility care. Standard 17. Investigation and management of non-obstructive azoospermia. Recommendations for practice. June 2014.

15. World Health Organization. WHO laboratory manual for the examination of human semen and sperm-cervical mucus interaction. 4th ed. Cambridge: Cambridge University Press; 1999.

16. Cooper TG, Noonan E, von Eckardstein S, et al. World Health Organization reference values for human semen characteristics. Human Reprod Update 2010;16:231-45.

17. Ho KL, Tsu JH, Tam PC, Yiu MK. Disease spectrum and treatment patterns in a local male infertility clinic. Hong Kong Med J 2015;21:5-9.

18. Tse JY, Yeung WS, Ng EH, et al. A comparative study of $Y$ chromosome microdeletions in infertile males from two Chinese populations. J Assist Reprod Genet 2002;19:376-83.

19. Li HW, Lee VC, Lau EY, Yeung WS, Ho PC, Ng EH. Role of baseline antral follicle count and anti-Mullerian hormone in prediction of cumulative live birth in the first in vitro fertilisation cycle: a retrospective cohort analysis. PLoS One 2013;8:e61095.

20. Crabbé E, Verheyen G, Silber S, et al. Enzymatic digestion of testicular tissue may rescue the intracytoplasmic sperm injection cycle in some patients with non-obstructive azoospermia. Hum Reprod 1998;13:2791-6.

21. Fu L, Xiong DK, Ding XP, et al. Genetic screening for chromosomal abnormalities and $\mathrm{Y}$ chromosome microdeletions in Chinese infertile men. J Assist Reprod Genet 2012;29:521-7.

22. Stahl PJ, Masson P, Mielnik A, Marean MB, Schlegel PN, Paduch DA. A decade of experience emphasizes that testing for $\mathrm{Y}$ microdeletions is essential in American men with azoospermia and severe oligozoospermia. Fertil Steril 2010;94:1753-6.

23. Bakircioglu ME, Ulug U, Erden HF, et al. Klinefelter syndrome: does it confer a bad prognosis in treatment of nonobstructive azoospermia? Fertil Steril 2011;95:1696-9.

24. Sabbaghian M, Modarresi T, Hosseinifar $H$, et al. Comparison of sperm retrieval and intracytoplasmic sperm injection outcome in patients with and without Klinefelter syndrome. Urology 2014;83:107-10.

25. Ozveri H, Kayabasoglu F, Demirel C, Donmez E. Outcomes of micro-dissection TESE in patients with non-mosaic Klinefelter's syndrome without hormonal treatment. Int J Fertil Steril 2015;8:421-8.

26. Rohayem J, Fricke R, Czeloth K, et al. Age and markers of Leydig cell function, but not of Sertoli cell function predict the success of sperm retrieval in adolescents and adults with Klinefelter's syndrome. Andrology 2015;3:868-75.

27. Mehta A, Paduch DA. Klinefelter syndrome: an argument for early aggressive hormonal and fertility management. Fertil Steril 2012;98:274-83.

28. Ng HY, Lau YL, Yeung SB, So WK, Tam PC, Ho PC. Testicular sperm extraction and intracytoplasmic sperm injection in non-obstructive azoospermia. Chinese Med J (Engl) 2000;113:246-50.

29. Levran D, Ginath S, Farhi J, Nahum H, Glezerman M, Weissman A. Timing of testicular sperm retrieval procedures and in vitro fertilization-intracytoplasmic sperm injection outcome. Fertil Steril 2001;76:380-3.

30. Karacan M, Alwaeely F, Erkan S, et al. Outcome of intracytoplasmic sperm injection cycles with fresh testicular spermatozoa obtained on the day of or the day before oocyte collection and with cryopreserved testicular sperm in patients with azoospermia. Fertil Steril 2013;100:975-80.

31. Bernie AM, Ramasamy R, Schlegel PN. Predictive factors of successful microdissection testicular sperm extraction. Basic Clin Androl 2013;23:5.

32. Ramasamy R, Lin K, Gosden LV, Rosenwaks Z, Palermo GD, Schlegel PN. High serum FSH levels in men with nonobstructive azoospermia does not affect success of microdissection testicular sperm extraction. Fertil Steril 2009;92:590-3.

33. Toulis KA, Iliadou PK, Venetis CA, et al. Inhibin B and anti-Müllerian hormone as markers of persistent spermatogenesis in men with non-obstructive azoospermia: a meta-analysis of diagnostic accuracy studies. Hum Reprod Update 2010;16:713-24.

34. Mitchell V, Boitrelle F, Pigny P, et al. Seminal plasma levels of anti-Müllerian hormone and inhibin $B$ are not predictive of testicular sperm retrieval in nonobstructive azoospermia: a study of 139 men. Fertil Steril 2010;94:2147-50.

35. Boitrelle F, Robin G, Marcelli F, et al. A predictive score for testicular sperm extraction quality and surgical ICSI outcome in non-obstructive azoospermia: a retrospective study. Hum Reprod 2011;26:3215-21.

36. Yang Q, Huang YP, Wang HX, et al. Follicle-stimulating hormone as a predictor for sperm retrieval rate in patients with nonobstructive azoospermia: a systematic review and meta-analysis. Asian J Androl 2015;17:281-4. 